\title{
Experimental and numerical analysis of scale deposition in a turbulent Taylor-Couette flow
}

JAKOB ROAR BENTZON ${ }^{1}$, BENAIAH U. ANABARAONYE ${ }^{2}$, SIMON IVAR ANDERSEN ${ }^{2}$, JENS HONORE WALTHER ${ }^{1,3}$, KAREN LOUISE FEILBERG ${ }^{2}$

${ }^{1}$ Department of Mechanical Engineering, Technical University of Denmark, Kgs. Lyngby, 2800, Denmark, jroben@mek.dtu.dk

${ }^{2}$ The Danish Hydrocarbon Research and Technology Centre, Technical University of Denmark, Kgs. Lyngby, 2800, Denmark

${ }^{3}$ Computational Science and Engineering Laboratory, ETH, $\underline{\text { Zürich, }} \underline{\mathrm{CH}}-8092$, Switzerland

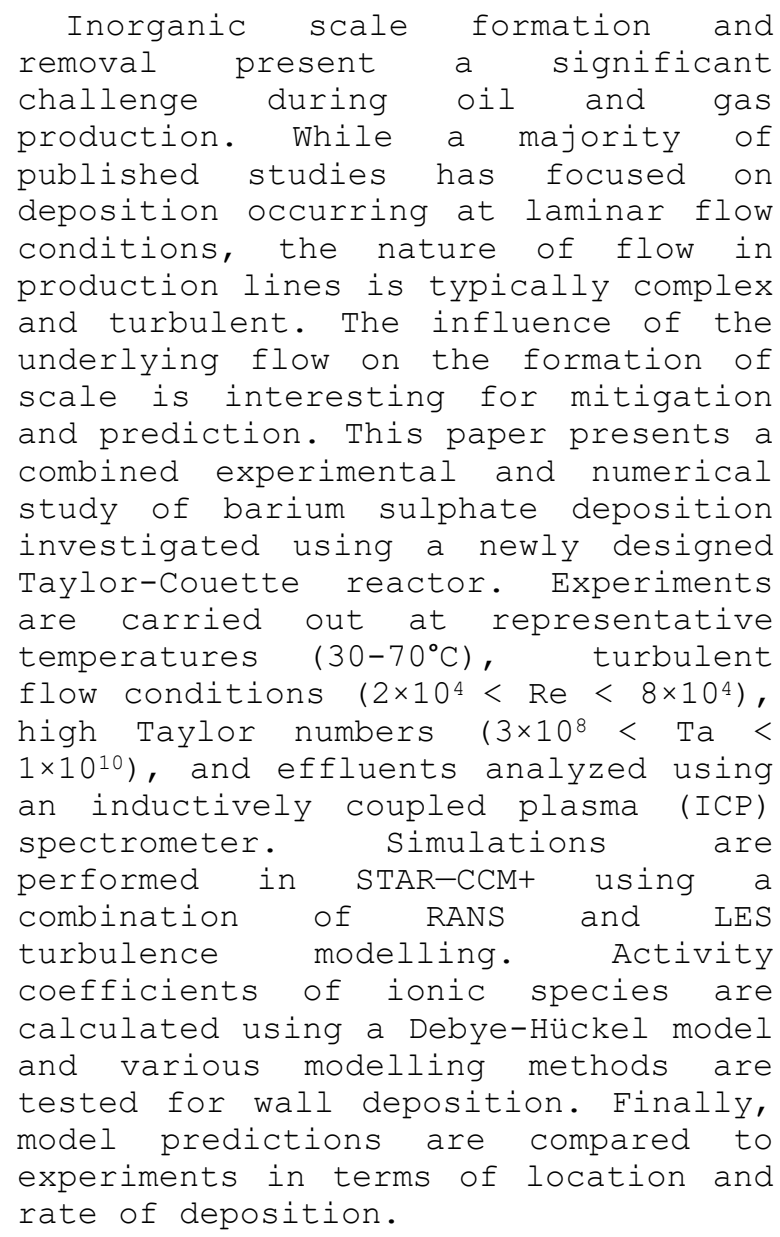

